\title{
AS CATEGORIAS CULTURA, HISTÓRIA E LIBERDADE COMO VECTORES NA EVOLUÇÃO E LEGITIMAÇÃO DA FILOSOFIA AFRICANA
}

\section{THE CATEGORIES OF CULTURE, HISTORY AND FREEDOM AS DRIVING FORCES IN THE EVOLUTION AND LEGITIMACY OF AFRICAN PHILOSOPHY}

\author{
Rosa Alfredo Mechiço ${ }^{1}$ \\ Recebido em: 05/2020 \\ Aprovado em: 06/2020
}

\begin{abstract}
Resumo: A filosofia africana é uma experiência/vivência e atitude humana, fruto da integridade e singularidade da cultura e das interações sociais, construída na ordem do acontecimento e do conhecimento. Apresenta-se como um dos instrumentos de tomada de consciência da identidade e alteridade do negro, uma das formas de regaste e reconhecimento da dignidade da cultura e dos valores do negro, um dos meios de negação da sua subalternização e submissão, resultado do mito da suposta superioridade do Ocidente (pressuposto da antropologia da Luzes) que levou à descriminação racial, cultural e ontolológica do Negro, igualmente, apresenta-se como condição da emancipação e contributo para a concretização da liberdade e da história do homem negro, na qual ele já não é figurante mas protagonista (sujeito e senhor) da sua história e do próprio destino. $\mathrm{O}$ estatuto e a legetimidade da filosofia africana encontram eco no interior da autencidade dos paradigmas e referenciais africanos, tais como a ética africana negra, estética negra africana, religiosidade africana, arte africana, o conceito de concepção familiar africana, tradição e sabedoria africanas (crenças colectivas, contos morais, lendas didácticas, aforismos, provérbios).
\end{abstract}

Palavras-chave: Categoria; Cultura; História; Liberdade; Legitimação.

Abstract: African Philosophy is an experience of life and human attitude that results of the integrity and uniqueness of culture and social interactions built on the event order and knowledge. It is presented as one of the instruments to make people aware of the identity and otherness of blacks, one of the ways of rescuing and recognizing the dignity of black culture and values, as well as, the means of denying their subordination and submission that result of the myth of supposed superiority of European People (Anthropology of Enlightenment assumption) that led to the racial, cultural and ontological discrimination of the black people, also presents itself as a condition for emancipation and contributes to freedom realization and the history of the black man, in which he isn't an extra, but a protagonist (master and subject) of his history and his own destiny. The status and legitimacy of African Philosophy finds an echo within the authenticity of African paradigms and references, such as: black African ethics, black African aesthetics, African religiosity, African art, the concept of African family design, African tradition and wisdom (African beliefs and collective stories, moral tales, didactic legends, aphorisms, proverbs).

Keywords: Category; Culture; History; Freedom; legitimation.

\footnotetext{
${ }^{1}$ Universidade Pedagógica de Maputo, Moçambique, rosamechico@gmail.com
} 


\section{Introdução}

\begin{abstract}
"I argue that philosophy is a universal intellectual activity that has been pursued by peoples of all cultures and that the propensity to raise fundamental questions about human experience can be found in peoples belonging to different cultures, even though the answers may be different, despite our common humanity, and may not all be equally compelling" (GYEKYE 1995, xiv Apud HALLEN, 2002, p. 29).
\end{abstract}

O presente ensaio pretende ser uma reflexão sobre a concepção da filosofia africana, sua evolução, suas bases, sua legitimação (reconhecimento) e progresso ao lado de outras filosofias e de outros campos do saber, a partir da releitura das obras de Elias Severino Ngoenha (Filosofia Africana: Das Independências às Liberdades, 1993), Barry Hallen (A Short History of African philosophy, 2002) e Richard H Bell (Understending African Philosophy: A Cross-Cultural Approach to Classical and Contemporary Issues, 2002).

A reflexão traz, à tona, os aspectos básicos que se encontram referenciados no pensamento destes autores em relação ao tema em questão, em razão disso, fundamenta-se, essencialmente, em dados documentados, isto é, bibliográficos.

No que concerne à metodologia, a reflexão em curso adopta a desconstrução e construção, acompanhada pela interpretação reflexiva e crítica.

Em termos de estrutura seguir-se-á a seguinte: após a introdução serão apresentados os pontos de partida que sustentam a reflexão sobre a filosofia africana, seguidos pelas questões de fundo que alimentam e retroalimentam o debate sobre a mesma. Consecutivamente, serão trazidas algumas condições julgadas como preliminares para a elaboração da filosofia africana. De seguida são desenvolvidos os aspectos ligados a querela entre a História e a Etnologia, entendida como o prelúdio da filosofia africana. Posto isto, apresentar-se-á o papel desempenhado pelos movimentos Negritude e African Personality e pela Etnofilosofia na arquitectura da Filosofia Africana. Sucessivamente serão reproduzidas e vincadas as marcas indeléveis das correntes Filosofia Crítica, Crítica da Crítica e Hermenêutica enquanto considerados os crivos na edificação e identificação da Filosofia Africana. Para terminar a reflexão abre-se um espaço onde evidencia-se o centro nevrálgico e gravitacional da Filosofia Africana: A Liberdade e a Historicidade. Por fim, são tecidas as considerações finais e apresentada a bibliografia usada como suporte teórico e científico da pesquisa. 


\section{Os pontos de partida da reflexão sobre a filosofia africana}

A filosofia é antes de tudo uma experiência/vivência humana, atitude, produto da cultura e das interacções sociais e com outras filosofias, dito por outras palavras, a "philosophy is a historial and well as cultural enterprise" (GYEKYE, 1995, xi-xii Apud HALLEN, 2002, p. 29). Por isso, torna-se inevitavelmente algo possível a todos os seres humanos (ocidentais e não ocidentais) e não exclusividade de alguns, "such new understanding is achieved piecemeal at greta cost, effort, and controversy" (HALLEN, 2002, p. 100). Portanto, ela existe em todo e qualquer lugar, embora por muito tempo o ocidente apregoou que, em relação a outros povos, sobretudo os africanos, somente ele é que se encontrava em melhores condições para desenvolver um discurso verdadeiramente filosófico.

No entanto, será então justo afirmar que, cada vez mais, fica claro o facto de que, sendo a filosofia um tipo de conhecimento que se constrói a partir da ordem do acontecimento e do conhecimento, sem receio, abre-se a infinitas possibilidades e formas de existência e realização, porquanto, "faz-se filosofia fazendo, o filosofar não deve estar preso às normas, conceitos e regras, pois tudo é movimento, assim a filosofia também é, é desterritorializada, e não necessita de donos" (MACHADO, 2012, p. 05).

Peremptoriamente, assume-se que a discussão sobre o estatuto e a legitimação da filosofia africana iniciou há mais ou menos 50 anos, quando esta foi introduzida como disciplina nas universidades africanas, seja como tema académico de investigação, debate e aprendizagem, conforme demonstra Bell:

African philosophy is currently in the process of formation by an active group of academic philosophers, critical theorists, and writers (almost all of whom are themselves Africans) who are refining its methods of reflections, the range of its concerns, and the particularity of its problems at this moment in time. Their discussions are of inherent and universal philosophical interest (BELL, 2002, p. XI).

Note-se a este propósito que ela nasce da preocupação dos filósofos africanos em:

(a) Afirmar a universalidade da filosofia e a possibilidade dela ser encontrada em outras culturas que não sejam ocidentais e expressa a partir de culturas autóctones, “(...) for various reasons, philosophy may be expressed found in different forms and formats in different cultural contexts (HENRY Apud HALLEN, 2002, p. 92) e, de igual modo, da vontade de 
elaborar essa filosofia própria, partindo de uma real adesão ao concreto, enraizada dentro de seu contexto histórico e social que passava por modificações profundas com o processo de emancipação da escravatura e descolonização que vários povos africanos atravessaram, processo de integração social dos negros nos países considerados do novo mundo, enfim, transformações políticas, económicas e sociais (MACHADO, 2012, pp. 15$16)$.

E também da necessidade de mostrar que "(...) philosophy is rich and ethnical diverse" (HALLEN, 2002, p. 93) e de incentivar a elaboração de uma tradição filosófica tradicional crítica a partir de realidades locais.

(b) Pensar e realizar a filosofia africana na condição de instrumento de emancipação e contributo para a concretização da história do homem e da mulher africanos, onde são chamados a ser protagonistas e senhores (autores e fazedores) da própria história e, em função disso, devem participar activamente no processo da elaboração e construção da mesma, pois não mais se trata de uma história inventada e imposta por outros, alheia às suas vontades, mas de seus próprios projectos de vida, com vista a um devir (futuro) melhor, a partir do conhecimento, análise e avaliação da África real e actual, através dos elementos e aspectos que a constituem e a mantêm, e não de uma África ideal e imaginária, fruto de viagens míticas do ocidente.

(c) Salientar que apesar dos projectos, debates e reflexões actuais que animam a filosofia africana, estarem voltados para o passado, ao invés de se voltarem para o futuro, como fazem os debates sociopolítico e económico, é preciso não perder de vista, que faz parte da essência da filosofia e do próprio filosofar posicionar-se de forma peculiar em relação ao futuro, por forma a perspectivá-lo e encará-lo positivamente. Todavia, à filosofia africana é permitida a volta ao seu passado histórico, apenas para desmistificar o futuro, "porque para desmistificar o futuro é necessário desmistificar a história" (NGOENHA, 1993, p. 12), (sobretudo quando se trata da nossa história africana, que foi feita a partir de modelos e interesses ocidentais). Desta forma, efectivamente, a volta ao passado histórico permitará simultaneamente "to restore an African sense of historial and intelectual continuity" (DIOP 1974 Apud HALLEN, 2002, p. 101).

(d) Asseverar que a filosofia africana é chamada e desafiada urgentemente a:

- Ser "a philosophy that sees human needs, interests, and dignity as of fundamental importance and concern” (GYEKYE, 1997, p.158 Apud BELL, 2002, pp. 39-40).

- Por um lado, "analisar e discutir a nossa história para que se abra um novo futuro, que não seja, portanto, simples prolongamento da história, para que possamos ser senhores 
do nosso destino e da nossa história" (NGOENHA, 1993, p.12). E, por outro lado, ajudar a imaginar, interrogar, escolher, projectar e tomar uma posição real sobre o futuro enquanto "conjunto de projectos, de possíveis, de esperanças, de liberdades, porque temos de escolher entre os diferentes possíveis ou criar outros. Se não formos capazes disto, o nosso futuro não será diferente do nosso passado" (Id.).

- Conhecer o papel (tarefa/missão) a desempenhar com relação a construção do futuro, de mais liberdade, desenvolvimento e autenticidade africana.

- Buscar conscientemente e de forma dinâmica o nosso lugar no universo da conjuntura histórica actual e futura, seja a nível ético (em que sistemas de valores acreditamos e queremos nos apoiar), a nível antropológico e existencial (que tipo de seres humanos pretendemos ser), a nível sociocultural (que tipo de sociedade e relações humanas almejamos), a nível político (que tipo de governo e regime político, longe de quaisquer condicionamentos ideológicos, consideramos como ideal, à medida que permite uma convivência pacífica e harmónica entre os homens), a nível económico (que modelo de economia se apresenta mais aberto e é de carácter desenvolvimentista, à medida que privilegia o livre intercâmbio do mercado financeiro).

- Tomar consciência da necessidade de assumir plenamente o compromisso e a responsabilidade de ocupar o nosso lugar da melhor forma possível, o que irá auxiliar, de forma ímpar, na construção da própria história e futuro.

\title{
As questões de fundo no debate filosofia africana
}

\author{
É inquestionável que a
}

Philosophy may arise from human language situations anywhere. It will be found wherever there are human beings expressing their deepest concerns, interests, and aspirations and where there is sufficient critical reflection on how best to give expression to those concerns, interests, and aspirations (BELL, 2002, p. 04).

Contudo, para que o africano participe activa e efectivamente na tradição filosófica, com a sua própria filosofia, é necessário que, a prior, tenha claro os motivos e o significado desse desafio importante, que deverá ser essencialmente na forma crítica da sua história passada e actual e mobilizadora de um futuro promissor, e interrogue sobre o estatuto dessa filosofia.

No seguimento do que se acabou de referir-se acima, em traços gerais, Barry Hallen 
(2002) afirma ser necessário questionar-se sobre até que ponto é possível elaborar, legitimar e reflectir sobre uma verdadeira e real filosofia africana, sendo que esta foi idealizada e elaborada a partir de metodologias (modelos conceptuais) advindas de culturas não africanas? Ou, dito por outras palavras, será que uma filosofia que se quer africana, mas feita a partir de paradigmas e referenciais não africanos merece ser legitimada como tal? (HALLEN, 2002, p. 90).

Neste contexto Hallen adverte que, sendo que os modelos usados para a reflexão sobre assuntos africanos não são africanos, é necessário que haja prudência, sobretudo quando essa metodologia é trazida para o âmbito da filosofia africana. É urgente que haja a consciência de que "Western and non-Western traditions do differ in the most fundamental manner over the substance of "philosophy"” (Ibid., p. 94).

Assim, imperatoriamente, Henry citada por Hallen afirma que a socióloga nigeriana Oyeronke Oyewumi em seus estudos, descobriu que muitos dos conceitos ligados à cultura ocidental quando impostos sobre às culturas africanas carregam uma bagagem filosófica diferente, e um significado que muitas vezes não tem nada a ver com o contexto africano, visto que tais conceitos distorcem a realidade africana, pois são aplicados para fins diferentes dos pré-concebidos e pré-estabelecidos na sua língua originária. (Ibid., p. 95).

Ainda nesta linha de pensamento temos Hountondji (1977) que no tocante à questão dos conceitos filosóficos, também se revela relutante quanto à negação de sua universalização (dos conceitos), porquanto, mesmos conceitos podem ter significados diferentes dependendo de culturas, e há vezes em que determinados conceitos não são encontrados, ou seja, não existem em outras culturas. Daí, chama atenção para a necessidade da distinção do uso popular do conceito filosofia enquanto ideologia e senso comum, do conceito filosofia no seu uso rigoroso, isto é, teórico.

\section{Condições preliminares para a elaboração da filosofia africana}

É importante aqui salientar que optar pela filosofia africana não significa negar ou rejeitar a filosofia ocidental, tão pouco equivale à ideia de criar um novo centrismo, mas a articular e adequar o discurso filosófico ao lugar de origem. De facto, ela pretende ser uma filosofia contextualizada, produzida e feita a partir de um espaço e tempo africano. Portanto, tratar-se-á de uma filosofia local, não de um lugar, mais concebida desde um lugar, a África, com o intuito de desalienar a consciência, buscar soluções para os problemas dos africanos, ser uma afirmação contra a dupla negação mormente a escravatura e a colonização, responder 
filosoficamente às concepções errôneas e preconceituosas do ocidente para com a África e à sua presunçosa superioridade em relação a todos os outros povos.

Neste enfoque, há que considerar, ainda, que actualmente vozes de grandes estudiosos africanos como Hountondji, Oruka, Soyinka, Diop, Appiah, Wiredu, Mudimbe, entre outros, levantam-se defendendo que os africanos podem e devem elaborar sua filosofia a partir de seus próprios referenciais, pois possuem condições para tal, "For then, and only then, will Africa's cultures be in a position to speak for themselves about what philosophy should or should not mean to them" (HALLEN, 2002, p. 91).

Todavia, a maior parte destes estudiosos deixa assente que é preciso ter em conta os seguintes aspectos:

(a) African philosophy is in the process of formation involving a larger intellectual community than just "professional" philosophers, attention must be given to such factors that are expressive of African's ordinary forms of life, i.e., through their orature, their traditional forms of governance, their fictional literature, and their arts. These are all forms of the narrative self-expression of Africans, and much that is within them are of critical significance to understanding African philosophy (BELL, 2002, p. xii).

(b) Criar a consciência de que "Philosophy in the African context does not have to replicate philosophy as defined and practiced in western culture" (Ibid., p. 99) e "rebuts the claims of those who insist that the philosophical enterprise in Africa must be a mirror image of philosophy in the west" (ORUKA, 1990a, pp. 45-46 Apud HALLEN, 2002, p. 52).

(c) Percorrer "um itinerário crítico, metódico e dialéctico em direcção a conquista de nós mesmos" (NGOENHA, 1993, p. 98), destacando a integridade e a singularidade das culturas africanas, e não fazer uma generalização apressada sobre todas as culturas do continente, pois este procedimento poderá não ter em conta as diversidades culturais que, de certo modo, também constituem herança cultural (NZEGWU 1998a, p. 4 Apud HALLEN, 2002, pp. 104105).

(d) Tornar clara e determinada a consciência sobre a identidade africana, aceitá-la, respeitá-la e valorizá-la, negar a subalternidade, a submissão e confirmar a alteridade, pois "we are a definitive stage of African self-liberation [that] is particularly crucial... On the continente [there] must come a reinstatemente of the values authentic to that society (...)" (SOYINKA 1976 Apud HALLEN, 2002, p. 91).

(e) Reivindicar o papel de sujeitos da nossa história (enquanto dimensão essencial da nossa existência e auto compreensão), que é diferente da história ocidental, mas que pelo facto de ser 
diferente, não deixa de ser válida. Perceber a história e a totalidade da mesma, partindo das partes para o todo, pois este exercício torna evidente que todos os homens, sem excepção, são sujeitos de direito da história, isto é, a história não é privilégio nem exclusividade de alguns e, por conseguinte, integrar a nossa história no conjunto das outras histórias, onde a nenhuma história particular é permitida colocar-se no centro em relação as outras histórias também particulares (NGOENHA, 1993, p. 51).

(f) "Like most African philosophers, Hountondji wants a fresh start-a break from ethnophilosophy and other "intellectual impediments and prejudices." But he also wants to carve out a more specific channel for African philosophy" (BELL, 2002, p. 28). A filosofia africana, segundo este autor, é um tipo de literatura produzido por africanos e que versa sobre problemas africanos. Por um lado, "num texto onde apresenta a missão da "fillosofia" em África, P. Hountondji insiste na consciência preliminar e na necessidade de destruir os mitos da "Africanidade" e mistificações herdadas dos "inventores" da África e da sua cultura" (MUDIMBE, 2013, p. 58) e, por outro lado, assevera que

a filosofia africana é resultado do pensamento abstracto de pensadores africanos individuais, tanto tradicionais como modernos. E, sobre este ponto de vista, a filosofia é dada como sendo uma reflexão racional e crítica sobre as ideias e os princípios mais fundamentais que subjazem ao pensamento no que se refere à vida humana e seu ambiente (Ibid., p. 150).

Ademais, deixa claro que a sua preocupação é a elaboração de uma filosofia africana que se assume como projecto intelectual de evolução científica e cultural africana, feito por africanos (filósofos individualmente identificados) para africanos, aberta a continuidade e mudança, liberta das formas metodológicas europeias e suas influências.

Diante disso, ao mesmo tempo que assume a posição acima

Hountondji realça a singularidade da tradição científica europeia e, ao mesmo tempo descreve o novo sujeito do pensamento, o filósofo africano, como um ser humano entre seres humanos, um intelectual entre os seus colegas e um membro de uma dada classe social (HOUNTONDJI, 1977, p. 70 Apud MUDIMBE, 2013, p. 60).

De modo igual, adverte que o debate a ser levado a cabo pelos filósofos africanos "não pode ser o eco longínquo dos debates europeus, mas um debate que confronte directamente os filósofos africanos entre si. [Porquanto,] O verdadeiro problema não é de falar $\boldsymbol{d} \boldsymbol{a}$ África, mas de discutir entre africanos" (HOUNTONDJI, 1977, p. 49 Apud TORRES, 2012, p. 18). 
(g) Ter a consciência clara no sentido de que a filosofia (universal) africana (particular/local) surge como uma alternativa de conhecimento e reflexão crítica diferente do etnocentrismo dos etnólogos ocidentais, responsável pela invenção reducionista e ideia monolítica sobre o continente africano e seus povos.

Ora, de acordo com o exposto acima, é imperioso assegurar que

a filosofia não paira além nem aquém da história. Ela é um seu produto. Como tal, ela é definida nos contornos do solo de onde emerge. Se filosofia é universal enquanto saber autónomo e produtora de conceitos, ela é também contextual, visto que os significados de seus conceitos são determinados de acordo com a lógica de lugar próprio. Isso não impede, no entanto, que os produtos singularizados pelo solo cultural de onde emerge tenham validade e pretensões universais. A fórmula já fora dada: quanto mais regional, mais universal. Assim, pautamos a filosofia africana desde suas estruturas sociais e, desde esse território político, económico e cultural (OLIVEIRA, 2006, p. 164 Apud MACHADO, 2012, p. 13).

\section{O prelúdio da filosofia africana: a querela história e etnologia}

Após as considerações precedentes, há que ter em devida conta que a investigação e a construção do discurso filosófico africano iniciaram "com aquilo que Hountondji chamou, um trabalho de etnologia com pretensão filosófica" (NGOENHA, 1993, p.15), diferentemente da filosofia ocidental que emergiu da história, enquanto dinâmica da sua situação específica. Mediante tal prudência, é importante sublinhar que,

a história e a etnologia constituíram-se como disciplinas afins e contraditórias, alimentando entre elas relações que derivam de duas categorias principais, tempo e espaço. Ambas são instrumentos de descrição do universo humano; mas a história faz o inventário do tempo e a etnologia do espaço (Ibid., p. 16).

Neste sentido, enquanto a história ocupou-se com o estudo das sociedades europeias, evoluídas, do branco corajoso e livre, tidas como civilizadas e perfeitas, porque com história, escrita e Estado, a etnologia interessou-se pelas sociedades exóticas, primitivas, do "negro feio", tidas como selvagens, bárbaras e imperfeitas, porque idólatras e de cultura arcaica, sem história, escrita e Estado. Logo, a "etnologia desenvolveu-se como um saber residual, definido negativamente em relação à história da Europa e da América do Norte" (NGOENHA, 1993, p. 17) e "criada como rejeição do outro" (Ibid., p. 18).

Conforme se pode depreender, o que no fundo também é história e com razão deveria ser considerado como tal, a partir de critérios ideológicos, tornou-se etnologia, anulando a 
identidade e colocando em causa o estatuto do Outro que não fosse ocidental, da unidade na diversidade e do respeito pelo diferente, trazendo à tona a incapacidade de perceber o outro homem como humano.

Com efeito, apesar dos avanços e progressos da humanidade no geral, a ciência do Séc. XIX continuou a vincar o forte e pobre argumento de não humanidade do negro, "colocou o negro, perto dos antepassados de todos os homens, os primatas, identificando assim o negro com o grau zero de evolução humana, na qual o homem branco representa o apogeu" (Ibid., p. 30). Outrossim, evidenciou de forma ridícula, a partir dos pressupostos da antropologia das luzes, que "os primitivos, eles representam portanto, um estádio ultrapassado da história" (Id.). Por conseguinte, "graças" à discriminação racial, cultural e ontológica, o negro destituído de sua humanidade, tornou-se propriedade do homem branco, o que abriu um largo caminho à escravatura dos africanos, sobretudo dos negros.

Desde já é oportuno destacar que a questão do racismo e da escravatura também teve um forte apoio no interior da tradição filosófica ocidental. Iniciou com Aristóteles, que deu ao negro africano o estatuto de escravo natural, continuou com os empiristas Locke e Hume e solidificou-se com o Code Noir (1685-1848), código jurídico composto por 60 artigos, promulgado por Luís XVI, que codifica a desumanização do negro, proclama e apela a destruição física do negro, sem possibilidade de nenhum tipo de recurso (Ibid., p. 29) e, teve seu auge com o romantismo alemão (Séc. XIX e XX), sobretudo, com o facto de a história passar a ser a história da razão e não dos factos, e "mais do que de historicidade do homem, fala-se do historicismo da razão, ou seja da coincidência da filosofia e da história" (Ibid., p. 34).

A bem dizer, as ideias e os acontecimentos acima referenciados, por um lado, aceleraram e agudizaram a negação, por parte do ocidente, da possibilidade de o negro possuir um espírito científico, por outro lado, facilitou o imperialismo e o colonialismo europeu, enquanto fenómenos sociocultural, político e económico, que deviam levar o suposto desenvolvimento e o progresso tecno-científico aos primitivos e selvagens africanos. Porquanto "colonizar, assim, era para o ocidente, arrancar os povos africanos à sua perdição, libertá-los das trevas, trazê-los à luz natural da razão, que ainda não possuíam; em resumo, humanizá-los” (NGOENHA, 1993, p. 79). Deste modo, nasceram as sociedades de etnologia de Paris em 1834 e de Londres em 1843, dando origem a antropologia como

ciência das sociedades primitivas ou tradicionais (...) dando caução científica aos discursos ideológicos, com vista a legitimar a "necessidade", até mesmo, a "racionalidade" da colonização. De facto, ela definiu sempre o que é diferente, a partir da sua experiência histórica, avaliou os outros à sua própria 
medida, e pensou a relação entre ela e o outro em termos dualísticos: de um lado o "simples", o primitivo e do outro, o complexo, o evoluído (Ibid., pp. 38-39).

Os factos colocam em evidência que na tentativa de resolução desta querela o mérito vai a um grupo de estudiosos, nomeadamente; F. Boas, este trouxe inovação à forma de proceder da etnologia, ao exigir que devia fazer o seu trabalho "sem teorias pré-concebidas nem projectos de explicação global e, avançava a ideia de que cada cultura humana tinha a sua história específica irredutível às outras culturas" (Ibid., p. 39).

Ao pensamento de Boas posteriormente juntam-se as ideias do antropólogo Malinowski, segundo o qual "todos os homens são iguais mas diferentes, e todas as diferenças são iguais" (Ibid., p. 40). Em seguida, do psicanalista Freud, que colocou "em causa a visão etnocêntrica do homem ocidental, como ser mais racional que os outros" (Id.). Logo depois, do sociólogo Durkheim, com a afirmação de que "já não se pode explicar a sociedade unicamente a partir da história ou da influência das outras culturas, doravante tinha de se encontrar a explicação nas próprias sociedades, isto é, na coerência estrutural e funcional” (Id.). Nesta senda, há que sublinhar, também, o contributo da Escola dos Anais, onde, através desta, a história redimensionou o seu campo de acção alargando o seu horizonte para história factual e a realidade concreta das massas e dos fenómenos sociais (Ibid., p. 41).

Dentre as diversas manifestações, resulta evidente qua as contribuições destes e de outros estudiosos foram decisivas para que a partir da década 60 iniciasse, de forma significativa, o abandono da distinção entre sociedades primitivas e evoluídas, fazendo-se com que o critério da explicação e interpretação da história fosse a partir da apreensão do outro na sua singularidade e da possibilidade da aceitação de que cada sociedade se torne uma outra sociedade (Id.).

Além disso, houve, por um lado, o esforço inequívoco de reaproximar-se à etnologia enquanto aquela que irá possibilitar a modificação das perspectivas cronológicas da história, e permitir a compreensão das especificidades concretas de qualquer sociedade, seja ela ocidental, africana, asiática, etc. Por outro lado, notou-se, de forma igual, o interesse em recarregar (carregar de novo) a etnologia da historicidade que lhe foi retirada e negada, com o propósito de que ela levará à consciência de que "as culturas humanas constroem-se uma em relação à outra, numa relação de alteridade, num fundo de identidade" (NGOENHA, 1933, p. 43), isto é, elas são produto de história particular, dinâmica e autêntica. Este exercício aconteceu com o intuito de eliminar-se o mito de superioridade ocidental (do ocidente como juiz do mundo e 
modelo/protótipo de perfeição, o que teve como consequência a imposição de modelos ocidentais a outros povos) e libertar a história do argumento ideológico, devolvendo à África a liberdade que lhe foi usurpada pelo ocidente, de modo que ela possa livremente e ao seu ritmo desenvolver-se.

Ainda assim, há, de certo modo, um mérito reconhecido aos especialistas e etnólogos britânicos e franceses, na medida em que indirectamente despertaram e ajudaram na "tomada de consciência da diversidade das culturas e à necessidade de respeitá-las, a fim de realizar com mais subtilidade a missão colonial" (Ibid., p. 53). Embora o objectivo primeiro não fosse o de cobrar o respeito pelas culturas autóctones em si mesmo e, "pôr a claro os valores e os sistemas de culturas, independentemente das suas origens" (Ibid., p. 56), mas para se evitar uma colonização cega, conflituosa e limitar os desgastos, a contribuição deles não deixa de ser valiosa.

É claro, portanto, que as teses por eles defendidas, por exemplo, a de que o "homem é antes de mais um ser social, isto é, ele é formado e informado pelo seu ambiente pela cultura na qual ele evolui (...) o homem não pode ser concebido, separado da sua cultura de origem" (Ibid., p. 54), ainda são válidas. O mérito vai também a Nova Escola etnológica, pelo esforço em redimensionar positivamente a visão sobre a África, tratando os povos ditos primitivos com mais objectividade e valor, chegando mesmo a afirmar que "não existem diferenças qualitativas entre a mentalidade primitiva e a mentalidade dos povos desenvolvidos” (Ibid., p. 56).

\section{O papel decisivo dos Movimentos Negritude e African Personality e da Etno-filosofia na arquitectura da filosofia africana}

Observe-se que, de qualquer forma, numa primeira análise é mister reconhecer que o desejo e a luta pela busca da afirmação negra e africana, isto é, da recuperação da autenticidade mais profunda, a partir da cultura e tradição negras, enquanto reforços da sociedade, iniciaram no exterior da África, nos EUA, com a elite intelectual de Harlem, Langston Hugnes, Chande Mckay, Jean Toomer, Countee Cullen, Sterling Brown, Du Bois, Blyden, com os jovens africanos Cesaíre, Senghor, Damas, Khrumah, na diáspora (Paris) e os que se encontravam no interior de África, com o jamaicano Garvey. Assume-se, no entanto, que todos estes deram origem aos movimentos New Negro, Harlem Renassaice (EUA) Negritude (África francesa e Antilhas), a Escola de Haiti (Antilhas), African Personality (África Anglófona), Back to África, etc., "The leading spokesman for the "negritude movement" was Léopold Senghor. He 
emphasizes the uniqueness of racial and cultural consciousness. The particularity of the African racial and cultural consciousness contributes to the idea of its singular cultural identity" (BELL, 2002, p. 24).

A este respeito, há que se evocar a relevância do Movimento Negritude, enquanto “ideologia capaz de criar uma base de luta comum para toda a raça negra" (NGOENHA, 1993, p. 73), à medida que terminantemente empenhou-se pela luta da não mais aceitação da opressão, despersonalização e humilhação racial do negro, da assimilação de valores e políticas ocidentais, mais sim libertação cultural, que no nível do discurso encontra eco na afirmação de Senghor (1964), que "sustenta que a libertação cultural é a condição preliminar da libertação política" (Ibid., p. 61) e, por isso, "repete inúmeras vezes, que considera a política simplesmente um aspecto da cultura" (Ibid., p. 62), defesa da própria qualidade de negro, descoberta e assunção dos valores e raízes do mundo negro, defesa do património racial e do espírito da própria civilização negra (Ibid., pp. 60-61).

De qualquer modo, o importante a reter, por ora, e que está contido, implicitamente no parágrafo acima, é que no nível da acção na busca pela identidade negra africana, a Negritude contou com os aspectos ética africana negra, estética negra africana, religiosidade africana, arte negra e com o conceito de concepção familiar africana.

Há que considerar neste contexto que ao lado do Movimento Negritude, que militava pela questão do resgate e reconhecimento da cultura Negra (Nacionalismo cultural), temos o movimento African Personality, iniciado por Blyden e depois retomado e assumido por Khrumah (militante do Pan-negro, mais tarde nacionalista africano convicto e, actualmente tido como o pai do pensamento político africano) e que vivamente afirmou: "Our philosophy must find its weapons in the environment and living conditions of the African people" (BELL, 2002, p. 39).

Em termos práticos, o African Personality exaltava e defendia a individualidade africana, a dignidade humana do africano, alargou a unidade política africana e os "atributos essenciais e únicos, que formavam a personalidade africana" (NGOENHA, 1993, p. 68), com o firme propósito de mante-los e desenvolve-los. Blyden "acreditava numa civilização africana milenária e viva, animada por valores morais espirituais elevados (...) via na África a “depositária espiritual do mundo"” (Ibid., p. 69).

Aparte isso, Nkrumah como nacionalista iniciou uma luta pela identidade geopolítica, isto é, uma luta que ultrapassava a raça negra e, abrangia todo o continente africano a partir da fusão harmônica de todo e qualquer povo e da tradição africana com "o objectivo de conter ao 
mesmo tempo a experiência africana da presença muçulmana e euro cristã, e da sociedade tradicional" (NGOENHA, 1993 p. 70), daí o seu "consciencismo", baseado na filosofia do desenvolvimento de cada indivíduo e na concepção de uma África una e unificada.

Por conseguinte, é útil aqui realçar que depois de Blyden (percursor da unidade africana), seguido por Josef Casely-Hayford (o primeiro teórico da unidade africana), temos Nkrumah como "o grande teórico da unidade africana, à qual dedicou um livro: “África deve unir-se"” (Ibid., p. 71), trata-se de unidade política, que faria da África uma só nação ou estado com único governo central.

No que diz respeito a Etno-filosofia, desde já, há que sublinhar a grandiosa obra "Filosofia Bantu" (1945) de Tempels, considerada o marco da filosofia escrita sobre a África. Esta filosofia teve como base os dados etnográficos e os da filosofia Escolástica. Com esta obra Tempels, pretendia construir uma filosofia sistemática do Negro, tendo como tese o argumento segundo o qual o negro tem humanidade, possui um pensamento lógico e, tem "um sistema de princípios que é um conjunto de ideias, um sistema lógico, uma filosofia completa do universo, do homem e das coisas que o circundam, da existência, da vida, da morte e da sobrevivência. Em suma, "uma ontologia logicamente coerente" (Ibid., p. 82).

Em virtude, porém, deste entendimento e com base na importância do mesmo levou-se a que a filosofia de Tempels se tornasse uma excelente etnologia. Note-se contudo, que ainda não é o Bantu que faz a sua própria filosofia mas o europeu, por meio da etnologia, posto que para Tempels o negro, apesar da sua humanidade, carece de um vocabulário adequado, exacto e de uma formação intelectual sistematicamente desenvolvido. Portanto, o Bantu possui uma filosofia sim, mas é uma filosofia de uma lógica menor, diferente da europeia na forma e no conteúdo, devido à sua ontologia que deriva do inconsciente, é directa, colectiva, imediata e não pessoal.

Por idênticas razões na linha de Tempels temos Kagame, autor da obra Filosofia Bantu Ruandês do Ser (1966). Este, como Tempels, também acreditava firmemente na existência de uma filosofia Bantu e, para demostrar a existência de tal filosofia, tomou como alicerce do seu estudo a filosofia aristotélica, fez uma reflexão a partir da língua Kiryarwanda, convicto de que ela era a chave para apreensão da concepção do universo por parte do Bantu, por isso, afirmou que "se existe uma filosofia no nosso substrato cultural, ela foi inevitavelmente formulada. De todos os documentos institucionalizados, a língua é sem margem de dúvida, a melhor formulação desta filosofia" (Ibid., p. 84).

Com efeito, Kagame supervalorizou a língua como meio para a demonstração da 
filosofia bantu, porque no seu entender, toda a estrutura linguística tem um carácter humano, uma formação lógica universal e uma formulação cultural, que transportam e traduzem aspectos mutáveis e peculiares de qualquer povo (NGOENHA, 1993, p. 84).

Pode se dizer que graças a contribuição destes dois homens (Tempels e Kagame) iniciou uma literatura considerável e rica sobre a reflexão filosófica africana, tendo como base os dados etnográficos.

\section{As correntes Filosofia Crítica, Crítica da Crítica e Hermenêutica: crivos na edificação e identificação da filosofia africana}

Segundo a divisão feita por Oruka (1990) a filosofia africana contemporânea é composta por quatro tendências ou correntes de pensamento: Etnofilosofia (Placide Temples, Alexis Kagame, Leopold Sedar Senghor, Jhon Mbiti, Griaule), Sagacidade Filosófica (Henry Odera Oruka), Filosofia Nacionalista-Ideológica ou Filosofia Política (Kwame Nkrumah, Julius Nyerere, Fannon, Dubois) e Filosofia Profissional ou Filosofia Crítica (Kwasi Wiredu, Paulin Hountondji, Eboussi Boulaga, Marcien Towa, Henry Oruka Odera, Peter Bodunrin, Ngoma Binda, Olabiyi Babalola), porém, nos últimos anos acrescentou-se à esta classificação mais duas correntes, a Filosofia Literária/Artística ou Poética (Wole Soyinka, Chinua Achebe, Oko p'Bitek, Ngugi wa Thiong'o) e a Filosofia Hermenêutica (Kwame Gyekye, Tshiamalenga Ntumba, Maurier, Lalêye, Barry Hallen, J. Olubi Sodipo) (HALLEN, 2002, p. 53).

De um modo geral, os críticos afirmam que o filósofo africano não deve ser observador e sintetizador de pensamentos já constituídos, imutáveis e as vezes incompletos, mais investigador livre, responsável e comprometido com a procura permanente da verdade e capaz de romper com os dogmas e os mitos. Deste modo, a filosofia africana deve deixar de ser um conjunto ou sistema de crenças, colectiva, espontânea, irreflectida, inconsciente, implícita e passar a ser criativa, possuidora de um carácter dinâmico, porém, sempre impregnado por um discurso coerente e lógico, posta em literatura (textos) capaz de ser interpretada e debatida. O crítico

Hountondji is best known for his critique, African Philosophy: Myth and Reality (1996), of philosophers in and of Africa who propound what he calls "ethnophilosophy." His intention is to condemn the intellectual injustice that he believes to be enshrined in publications purporting to be African philosophy when they display the following essential characteristics. Ethnophilosophy presents itself as a philosophy of peoples rather than of individuals (Ibid., p. 50). 
$\mathrm{Na}$ verdade ele sustenta a ideia da necessidade da literatura filosófica africana, que deve colocar por escrito tudo o que é literatura oral, pois enquanto não se fizer este exercício a tradição oral (contos morais, lendas didácticas, aforismos, provérbios, etc.) permanecerão uma sabedoria e não filosofia, porém

transcrevendo-as, podemos conferir-lhes o valor de documentos filosóficos, isto é, podem servir de suposto para uma reflexão crítica e livre, e marcar com isso, o início de uma revolução no interior do problema da filosofia africana: uma nova estrutura teórica para a história da nossa filosofia (NGOENHA, 1993, p. 92).

Ora, em continuidade com o exposto acima Hountondji assevera que a

Oral tradition favours the consolidation of knowledge into dogmatic, intangible systems, whereas archival transmission promotes better the possibility of a critique of knowledge between individuals and from one generation to another. Oral tradition is dominated by the fear of forgetting, of lapses of memory, since memory is here left to its own resources, bereft of external or material support. This forces people to hoard their memories jealously, to recall them constantly, to repeat them continually, accumulating and heaping them up in a global wisdom, simultaneously present, always ready to be applied, perpetually available. In these conditions the mind is too precoccupied with preserving knowledge to find freedom to criticise it. Written tradition, on the contrary, providing a material support, liberates the memory, and permits it to forget its acquisitions, provisionally to reject or question them, because it knows that it can at any moment recapture them if need be. By guaranteeing a permanent record, archives make actual memory superfluous and give full rein to the boldness of the mind (HOUNTONDJI, 1996, p. 103 Apud BELL, 2002, pp. 28-29).

Outrossim, defende a ideia de que "a filosofia só pode desenvolver-se plenamente escrevendo as próprias memórias: conservando o seu jornal” (NGOENHA, 1993, p.92), uma vez que o escrito, a partir do registro, cria arquivo, garante memória, transmissão e difusão do conhecimento, abre espaço para crítica, debates e discussões futuras, enquanto a tradição oral tende a ser um sistema rigorosamente dogmático e repetitivo, é sujeito ao esquecimento e a ser viciado conforme os interesses de quem a invoca e, fecha as oportunidades para a crítica, por isso, é mais tradicionalista e conservadora.

$\mathrm{Na}$ crítica da crítica evidenciaram-se os estudiosos Babalola, Dieng e Binda. Babalola levanta questões importantes, a saber; (a) que caminho a filosofia africana deve percorrer de modo a erguer-se como tal, o mesmo que a Grécia percorreu ou deve seguir seu próprio 
itinerário? (b) o critério para que a nossa filosofia seja reconhecida é europeizar-se? E adianta as seguintes ideias, (c) ao se edificar a filosofia africana deve-se precaver contra o etnocentrismo filosófico ocidental, (d) antes de mais os africanos devem preocupar-se com a construção de uma tradição teórica, científica, aberta, responsável pelos assuntos que aborda e capaz de contribuir para a emancipação e desenvolvimento da África (Ibid., p. 102).

No que concerne à corrente hermenêutica, importa referir que trata-se de uma corrente muito actual, seu objectivo é essencialmente trazer soluções às necessidades e preocupações da África real e actual e assevera que "The "philosophy" here, however, is not so much in what is said but by how it is interpreted. Although it looks at first-order speech, what is philosophical is the second-order critique of that speech and that, of course, is written" (BELL, 2002, p. 33).

Em seu âmago, a hermenêutica rejeita a etnofilosofia como capaz de elaborar uma filosofia africana, mas considera-a sabedoria africana, aquela que deve ser o pilar na edificação da filosofia africana, tomada como projecto futuro e não algo elaborado e que se deve revelar e, avança com a ideia de que o filósofo africano deve reler e interpretar a tradição à luz do presente, de modo a torná-la actual e actuante (NGOENHA, 1993, p. 105).

De certo modo, se o que se acabou de afirmar no parágrafo anterior constitui verdade, será então justo e importante reconhecer que todo o ser humano (in)directamente realiza actividades e toma atitudes filosóficas, embora isto não constitua de per si um pensamento filosófico, por isso, baseando-se na etimologia do termo filosofia, "devemos pensar a filosofia com uma actividade possível a qualquer homem" (Ibid., p. 108) e repudiar a ideia de que a ausência da escrita é sinónimo de não existência da filosofia africana

Resulta claro, portanto, que Lalêye (1970) enquanto apoiante desta corrente, para além da tradição aposta também na religião africana, não como “conditio sine quo non", mas um excelente ponto de partida na investigação da essência do pensamento e discurso filosófico africano. Sendo contra a renúncia total do mito levanta a questão da necessidade da revalorização razoável (não extrema e exagerada) do mito e sua reinserção no interior do discurso filosófico, tendo como base a tarefa desempenhada por este nos diálogos de Platão (Ibid., pp. 106-107) e que ainda desempenha nos nossos dias, pois, “o mito está, portanto, sempre presente em toda a reflexão, até mesmo de tipo estritamente filosófico e por isso não é possível a sua eliminação total. Aliás o mito faz parte da actividade filosófica real. (...) o mito tem um lugar de capital importância na especulação filosófica” (Ibid., p. 107).

\section{O Centro Nevrálgico e Gravitacional da Filosofia Africana: A Liberdade e a Historicidade}


A maior parte dos movimentos da consciência africana do final do Séc. XX tinham o mesmo espírito e tendiam a única finalidade: a liberdade do negro vista como condição de sua historicidade.

Ora, a aspiração pela liberdade realizou-se dentro de um conflito constante de culturas, em que a modernidade opunha-se à tradição, com uma notável divisão entre os africanos; tradicionalistas e modernos e, é esta divisão da alma africana que constituiu a base da crise da consciência africana moderna. Este perigo convidou a "filosofia africana a conceber novas formas a dar, à inevitável luta de libertação" (Ibid., p. 112), pois se havia ganho a consciência de que "nenhum progresso no debate filosófico africano será legítimo se não tiver dado a solução a este problema, cuja primazia advém não simplesmente da cronologia, mas sobretudo da ontologia" (NGOEHA, 1993, p.112).

Afigura-se relevante evidenciar "que a compreensão das coisas ou dos eventos históricos é uma espécie de hermenêutica da liberdade humana" (Ibid., p. 117), sobretudo

daquela liberdade que já atingimos mas ainda nos falta conquistar; as nossas culturas tradicionais, que nos ajudaram a suportar pesos indizíveis e serviram de suporte cultural ao esforço de luta pela liberdade. E portanto, para que esta longa marcha em direcção à liberdade continue, temos que sofrer as leis da mudança temporal de uma maneira consciente (...) e pormo-nos ao lado da cultura (Ibid., p. 119).

Outrossim, é urgente reconhecer que

as liberdades individuais não são simplesmente a reafirmação kantiana da pessoa-fim e da sua dignidade e autonomia, mas é o principio activo da política e dos estados, o metro da sua organização e do seu funcionamento. As liberdades individuais realizam-se nas instituições democráticas que são proclamadas e realizadas através de princípios ideais, de instituições jurídicas e de relações factuais que lhe desenham o vulto e lhe afinam continuamente a fisionomia. A relação entre as liberdades individuais e as colectividades políticas leva imediatamente o indivíduo a transferir-se ao colectivo, pois que, como é óbvio, a dignidade abstracta e a autonomia da pessoa-fim vive concretamente no sistema de acção social que acolhe o agir individual, como agir em vista do outro e que progressivamente se estrutura em conjunto colectivos e, portanto, em ordenamentos sociais (Ibid., pp. 156-157).

Na perspectiva de Bell "For this reason we are forced to seek our own original mode, a Negro-African mode (...) paying special attention to (...) economic democracy and spiritual freedom" (SENGHOR, 1964, p. 442 Apud BELL, 2002, p. 38). Foi igualmente neste contexto 
que a filosofia africana assumiu como principal objectivo a conquista e preservação da liberdade do povo negro (liberdade política da imposição e submissão colonial, liberdade económica, social, cultural, tradicional e religiosa), enquanto condição para a afirmação da sua historicidade, alteridade e humanidade, rejeitados e negados pelo ocidente, de modo que, o africano passe de objecto para sujeito de sua história e se aproprie de seus projectos.

As considerações acima provam que a filosofia africana, desde a sua origem, teve como sua grande pretensão: a) assumir a questão existencial do negro a partir da síntese fenomenológica, da crítica global e significativa da história que, de forma dinâmica, vai construindo (que saí da história morta e nostálgica para a história positiva e operativa, enquanto passado que influencia e condiciona toda e qualquer realização temporal), b) perceber em que medida é histórica a auto-compreensão que ela tem de si e até que ponto esta auto-compreensão modifica a concepção da sua história e, c) ajudar na percepção do papel, significado e contributo da presença dos valores e actuação da estrutura cultural e tradicional africana na civilização no geral (NGOENHA, 1993, p. 112).

Isto explica também por que razão, decididamente, Ngoenha assegura que "a história não é simplesmente memória, mas sobretudo projecção para frente, sentido do futuro, como atestado da liberdade" (Ibid., p. 115), daí que a sua adesão supõe uma reflexão a partir da ética situacional para uma melhor avaliação das fases da sua evolução e progressão. Para além disso, reitera também que, na história a reflexão filosófica encontra a inteligibilidade e o valor dos actos humanos e, "as relevâncias históricas tornam-se luminosas, radicais e clarificadoras do sentido dos factos e das dinâmicas antropológicas” (Ibid., p. 121).

Em virtude, porém, do facto de a história enquanto sequência e sucessão de eventos positivos e negativos, e com base também em suas peculiaridades a saber: tradição de factos e acções de sujeitos, projecto aberto, imprevisível, sem garantias objectivas de sucesso, construído a partir de possibilidades e capacidades dos seus intervenientes, deve, por um lado, integrar o passado de modo a "emergir sincronicamente todos os elementos que evidenciam as características de uma determinada civilização, diferenciando-a das outras” (Id.), posto que não existe história comum a todos os homens, e de outro lado, deve revelar as identidades primárias e a forma particular de cada povo participar na história e, por consequência, guiar-nos para uma história futura mais humana.

À terminar duas observações, entretanto, se fazem necessárias a respeito do assunto. Em primeiro lugar é o facto de a tomada de consciência de sujeitos éticos e históricos ser categoricamente imprescindível para a captação da realidade histórica e sua interpretação. Em 
segundo lugar é o compromisso de tomada de posição perante a história, que passa necessariamente pela emissão do juízo de valor do discurso histórico, enquanto suporte no esforço de luta pela busca da liberdade e sua afirmação.

\section{Considerações Finais}

Num certo sentido, poder-se-ia afirmar, então, que a filosofia enquanto carácter universal da actividade humana não é privilégio de alguns indivíduos, mas está presente em todas as culturas humanas e em constante relação com elas, porquanto a filosofia é essencialmente um fenómeno cultural, por isso, indiscutivelmente universal.

Para o caso particular da filosofia africana, é legítimo afirmar que ela surge e evolui, por um lado, como reivindicação e afirmação da história e liberdade negados e rejeitados ao africano, sobretudo ao africano negro, pelo Ocidente, por outro lado, como negação e refutação da ideia de que a filosofia é monopólio exclusivo do Ocidente.

De um modo geral, os autores em estudo convergem na ideia segundo a qual o importante não é a procura por uma filosofia africana, mas pensar filosoficamente a nossa realidade africana. Seguramente, este posicionamento faz com que aquela velha questão de saber se existe ou não uma filosofia em África dê lugar à questão de saber se a África realmente tem necessidade de possuir a sua própria filosofia. Daqui, depreende-se pois que não basta a preocupação pela demonstração da existência da filosofia africana, é também importante e, sobretudo, significativo o reconhecimento do valor e do papel dessa filosofia, quer na exaltação da nossa identidade, portanto das nossas origens, quanto na auto-afirmação da nossa dignidade e na emancipação negro africana, sem no entanto descurar a sua função quanto ao futuro e destino africanos.

Assim, na realidade concreta assume-se que a filosofia africana mais do que algo seguro e um dado adquirido deve ser pensada e encarrada como um projecto do futuro, essencialmente aberto e descontínuo, uma história criativa e libertadora.

Ademais, é mister abandonar a acentuação exagerada à economia, ciência e técnica como critérios fundamentais que dão sentido e validade à história e, dar-se lugar ao conceito humanidade (ligado sobretudo às questões do bem-estar, em todas as suas vertentes, isto é, ao progresso humano e social, aos valores solidariedade, igualdade de direitos, liberdade, respeito, paz, harmonia, cooperação, tolerância, etc.) como critério e motor da história.

Nos tempos actuais à filosofia cabe, de modo geral e especial, orientar a sociedade e o 
próprio ser humano em suas escolhas, tendo em conta as seguintes questões: o que é que nós somos ou simplesmente quem somos, queremos e devemos ser, indicando dentro dos dados sociológicos, antropológicos, axiológicos e epistemológicos os meios adequados para os fins propostos, de forma a permitir um futuro que seja de acordo com o universo humano e, por conseguinte, beneficie a todo o universo sem nenhuma excepção.

\section{Bibliografia}

APPIAH, Kwame Anthony. Na Casa do meu Pai: A África na filosofia da cultura. Contraponto Editora, Rio de Janeiro, 1997.

BELL, H. Richard. Understanding African Philosophy: A Cross-Cultural Approach to Classical and Contemporary Issues. Routledge New York and London, 2002.

HALLEN, Barry. A Short History of African Philosophy. Indiana University Press, Bloomington, USA, 2002.

HOUNTONDJI Paulin J.. Sur la « Philosophie Africaine » - Critique de l'ethnophilosophie. Paris, Maspéro, 1977.

HOUNTONDJI Paulin J.. Conhecimento de África, conhecimento de Africanos: Duas perspectivas sobre os Estudos Africanos. In: SANTOS, Boaventura de Sousa; MENESES, Maria Paula, (Org.), Revista crítica de ciências sociais (RCCS), Ed. Almedina, Coimbra, Número 80, Março 2008, p.149-160.

MACHADO, Adilbênia Freire. Filosofia Africana e currículo: Aproximações. Revista SulAmericana de Filosofia e Educação - RESAFE, Número 18, Maio-Outubro/2012, p. 4-27.

MUDIMBE, V. Y. A Invenção de África: Gnose, Filosofia e a ordem do Conhecimento. Edições Pedago e Mulemba, Portugal-Angola, 2013.

NGOENHA, Severino Elias. Filosofia Africana: Das Independências às Liberdades. Edições Paulistas, Maputo, 1993.

TORRES, Adelino. Filosofia Africana e Desenvolvimento - CIS, 22.10.2012, Em linha www.adelinotorres.com 